\title{
La mente y la medicina
}

\section{The mind and medicine}

\author{
Martínez Anahí ${ }^{a}$
}

\begin{abstract}
:
The mind plays a very important role in the area of health, since the presence of the disease is dominated by emotion and fear because on many occasions they relate the disease to death which causes a state of invulnerability. The doctor, nurse or health personnel are responsible for working on the clinical disorder, as well as on those ailments, or for calming the patient and preventing his or her mind from taking hold of it, causing fear or suffering. Which means dealing with the physical ailments without neglecting the emotions of the patients.
\end{abstract}

Keywords:

Mind, emotion, fear, disease, death, clinical disorder.

Resumen:

La mente juega un papel muy importante en el área de la salud, ya que la presencia de la enfermedad está dominada por la emoción y por el miedo pues en muchas ocasiones relacionan a la enfermedad con la muerte lo cual provoca un estado de invulnerabilidad. El médico, enfermera o personal de salud son los encargados de trabajar en el desorden clínico, así como en esas dolencias o bien tranquilizar al paciente e impedir que su mente se apodere de este, provocando miedo o sufrimiento. Lo que quiere decir ocuparse de las dolencias físicas sin descuidar las emociones de los pacientes.

Palabras Clave:

Mente, emoción, miedo, enfermedad, muerte, desorden clínico.

\section{Introducción}

La inteligencia emocional consiste en la habilidad que se tiene para percibir y evaluar las emociones, pues esta suele componerse de varias capacidades, entre ellas:

- Percibir correctamente las emociones.

- Usarlas e identificarlas adecuadamente.

- Comprenderlas.

Todo esto para lograr regularlas eficazmente y lograr tener una inteligencia emocional de calidad.

En el área de la salud se logra comprobar o corroborar que el presentar una inteligencia emocional en alto nivel nos ayudará o bien nos permitirá regular de una manera efectiva las emociones negativas.

Como bien sabemos "salud" se refiere tanto al bienestar, físico, mental y social.

Es común que cuando hay algo que afecta a nuestras emociones, nuestro cuerpo reacciona de alguna u otra manera

Es por ello que lo que buscamos como personal de salud no solo es trata de estabilizar o trabajar en el desorden clínico si no en equilibrar la relación entre la mente y el cuerpo, ya que lo que se acumula en la mente puede predisponer a estrés y por ende algunas enfermedades 0 bien retrasar la recuperación de estas.

\section{Marco teórico}


La enfermedad puede desencadenarse por diversas razones, dentro de las cuales no se menosprecia la inteligencia emocional en desorden ya que debido a esto la mente nos puede hacer una mala jugada pues al haber presencia de alguna patología, examen medico o exploración, son dominados por las emociones, principalmente por el miedo lo cual puede ocasionar inseguridades y fragilidad emocional, esto debido a que muchos pacientes asocian a la enfermedad con invulnerabilidad o muerte, especialmente a la enfermedad grave.

En muchas ocasiones, los pacientes se precipitan al tener un diagnostico real y comienzan a imaginarse o auto diagnosticarse, piden encontrarse solos, volviéndose débiles, indefensos y desamparados.

Debido a lo mencionado anteriormente el personal de salud juega un papel de suma importancia, ya que muchos de los que forman parte de este personal, solo se ocupan de las dolencias físicas descuidando las reacciones emocionales de los pacientes ante la presencia de la enfermedad. Y esta falta de atención emocional hacia el enfermo implica una dificultad en el proceso de recuperación.

Actualmente la medicina moderna se ha ocupado de la curación de la enfermedad dejando a un lado el sufrimiento del paciente.

Por lo que con el pasar del tiempo y las diversas situaciones a las que nos enfrentamos a nivel mundial, la atención médica y enfermera trata de caracterizarse por ser emocionalmente muy inteligente, esto gracias a la preocupación por la dolencia ante su enfermedad, el desequilibrio emocional como por el desorden clínico del paciente.

Por tanto, nosotros tenemos un gran poder ante nuestra salud, creemos que una receta médica es la que nos va a facilitar una recuperación, pero no es tanto por el tratamiento que prescriben si no por la autoridad que atribuyen, por la esperanza que les dan ante una recuperación. También el realizar actividades divertidas, en las cuales nuestra mente se despeje y no se tenga enfocada en la enfermedad, ayudan a reducir las visitas al médico, lo cual quiere decir que un cambio positivo en la actitud mental nos ayuda a mejorar la calidad de vida, pues una actividad placentera se vincula a una vida saludable ya que ayuda a una buena recuperación o reducir el riesgo de padecer enfermedades del corazón o un ictus.

\section{Conclusión}

En conclusión, la inteligencia emocional se ve alterada en la presencia de la enfermedad, debido a que nos provoca un estado de invulnerabilidad. Es por ello que el tener esperanza, creencias 0 pensamientos positivos, podremos sanar el cuerpo.

Como personal de salud puedo destacar que nuestro trabajo no solo se limita a crear un diagnostico y tratamiento si no también en ser emocionalmente inteligente y brindar apoyo moral y emocional a todo paciente que esté pasando por una dolencia, perdida 0 inseguridad. $Y$ una oportunidad que debemos de aprovechar para hacerlo es durante la amnesis, mientras realizamos esta podemos tranquilizarlo, ser amables, afectuoso y darle esperanzas.

Es bien sabido que hay muchos pacientes y se satura el área hospitalaria pero no es justificación para mostrarnos indiferentes ante el padecimiento de nuestros pacientes, pues no nos quita mucho tiempo el brindar unas palabras de aliento.

\section{Referencias}

[1] Goleman, D., González Raga, D. and Mora, F., 2009. Inteligencia emocional. Barcelona: Kairós, pp.143-149. 